WellBeing International

WBI Studies Repository

$4-2005$

\title{
Carbon Dioxide for Euthanasia: Concerns Regarding Pain and Distress, with Special Reference to Mice and Rats
}

\author{
Kathleen Conlee \\ The Humane Society of the United States \\ Martin Stephens \\ The Humane Society of the United States \\ Andrew N. Rowan \\ The Humane Society of the United States \\ Lesley A. King \\ Oxford University
}

Follow this and additional works at: https://www.wellbeingintlstudiesrepository.org/acwp_lab

Part of the Animal Studies Commons, Bioethics and Medical Ethics Commons, and the Other Veterinary Medicine Commons

\section{Recommended Citation}

Conlee, K. M., Stephens, M. L., Rowan, A. N., \& King, L. A. (2005). Carbon dioxide for euthanasia: concerns regarding pain and distress, with special reference to mice and rats. Laboratory Animals, 39(2), 137-161.

This material is brought to you for free and open access by WellBeing International. It has been accepted for inclusion by an authorized administrator of the WBI Studies Repository. For more information, please contact wbisr-info@wellbeingintl.org.

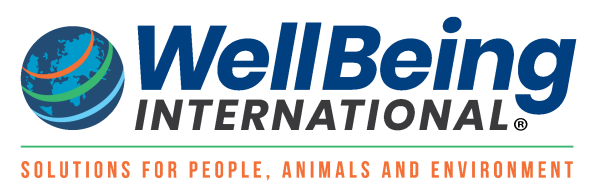




\title{
Carbon dioxide for euthanasia: concerns regarding pain and distress, with special reference to mice and rats
}

\author{
K M Conlee ${ }^{1}$, M L Stephens ${ }^{1}$, A N Rowan ${ }^{1}$ and L A King ${ }^{2}$
}

${ }^{1}$ The Humane Society of the United States, Animal Research Issues, 2100 L Street NW, Washington, DC 20037, USA; ${ }^{2}$ Linacre College, Oxford University, St Cross Road, Oxford OX1 3PS, UK

\section{Summary}

Carbon dioxide $\left(\mathrm{CO}_{2}\right)$ is the most commonly used agent for euthanasia of laboratory rodents, used on an estimated tens of millions of laboratory rodents per year worldwide, yet there is a growing body of evidence indicating that exposure to $\mathrm{CO}_{2}$ causes more than momentary pain and distress in these and other animals. We reviewed the available literature on the use of $\mathrm{CO}_{2}$ for euthanasia (as well as anaesthesia) and also informally canvassed laboratory animal personnel for their opinions regarding this topic. Our review addresses key issues such as $\mathrm{CO}_{2}$ flow rate and final concentration, presence of oxygen, and prefilled chambers (the animal is added to the chamber once a predetermined concentration and flow rate have been reached) versus gradual induction (the animal is put into an empty chamber and the gas agent(s) is gradually introduced at a fixed rate). Internationally, animal research standards specify that any procedure that would cause pain or distress in humans should be assumed to do so in non-human animals as well (Public Health Service 1986, US Department of Agriculture 1997, Organization for Economic Cooperation and Development 2000).

European Union guidelines, however, specify a certain threshold of pain or distress, such as 'skilled insertion of a hypodermic needle', as the starting point at which regulation of the use of animals in experimental or other scientific procedures begins (Biotechnology Regulatory Atlas n.d.). There is clear evidence in the human literature that $\mathrm{CO}_{2}$ exposure is painful and distressful, while the non-human literature is equivocal. However, the fact that a number of studies do conclude that $\mathrm{CO}_{2}$ causes pain and distress in animals indicates a need for careful reconsideration of its use. Finally, this review offers recommendations for alternatives to the use of $\mathrm{CO}_{2}$ as a euthanasia agent.

Keywords Carbon dioxide; euthanasia; pain; distress; anaesthesia; welfare; rodents

Carbon dioxide $\left(\mathrm{CO}_{2}\right)$ is commonly used for euthanasia and anaesthesia of laboratory rodents, largely because of its ease of use, relative safety, and low cost, as well as its capacity to euthanize large numbers of animals in a short time span (Ambrose et al. 2000). In large institutions and those with significant rodent-breeding programmes, large numbers of rodents are often euthanized in a short time (Kline et al. 1963) Correspondence: K M Conlee. Email: kconlee@hsus.org and an appropriate gas agent is often the best way to approach such a challenge. However, $\mathrm{CO}_{2}$ is not physiologically inert and the published evidence on whether or not $\mathrm{CO}_{2}$ administration causes pain or distress in animals raises questions about its routine use. This paper reviews this published evidence and includes information on the effects of $\mathrm{CO}_{2}$ in both humans and nonhumans. Methodological details are included when possible in order to provide a clear 
picture of how studies were conducted.

Alternatives to the use of $\mathrm{CO}_{2}$ as a sole agent for euthanasia are also suggested.

Animal welfare should be the main factor taken into consideration when choosing an appropriate method of euthanasia (American Veterinary Medical Association [AVMA] 2001). The least stressful procedure should be utilized whenever possible - the term 'euthanasia' being derived from a Greek term meaning 'good death.'

The current standards for euthanasia in the US are set out in the 2000 Report of the AVMA Panel on Euthanasia. This report, written by the AVMA (2001), indicates that a 'good death' is one 'that occurs without pain and distress' and 'the technique should minimize any stress and anxiety experienced by the animal prior to unconsciousness'. Similar statements are indicated in various international guidelines and recommendations regarding euthanasia (e.g. Canadian Council on Animal Care [CCAC] 1993, Close et al. 1996, 1997, ANZCCART 2001).

Existing guidelines offer no clear, quantitative guidance on what techniques might be considered 'without pain and distress' nor what would qualify as 'rapid unconsciousness' - seconds, tens of seconds, minutes? Nonetheless, the literature on decapitation gives some sense of what may not be acceptable in regards to length of time. The 1986 and 1993 AVMA reports on euthanasia cautioned against the use of decapitation because a single study of rats found that the decapitated head continued to produce electroencephalogram (EEG) traces for an average of $13.6 \mathrm{~s}$ after decapitation (5.6-29.5 s) (see references in AVMA 2001). Therefore, due to lack of information, such times specified in guidelines can start to guide us. The published literature indicates that $\mathrm{CO}_{2}$, at least under some circumstances, causes pain and distress and does so for longer than $10 \mathrm{~s}$ (there are conflicting reports regarding duration, but $10 \mathrm{~s}$ is the minimal amount of time reported in the literature reviewed). Despite the evidence in the published literature that $\mathrm{CO}_{2}$ causes distress, the authors have received anecdotal reports from laboratory animal veterinarians that $\mathrm{CO}_{2}$ appears humane when euthanasia is done properly by welltrained personnel.

\section{Existing policies relevant to this issue}

The Organization for Economic Cooperation and Development (OECD) guidance document on humane endpoints follows the principle that if something is known to cause pain, distress and suffering in humans, it should be assumed to cause the same in animals (OECD 2000). This principle is also included in animal research regulations and guidelines in the United States, including those promulgated by the United States Department of Agriculture (1997) and the Public Health Service (1993), as well as those in other countries (e.g. CCAC 1993). As mentioned, European Union guidelines follow this principle but specify a certain threshold of pain or distress for regulating animal use, for example using 'skilled insertion of a hypodermic needle' as guidance (Biotechnology Regulatory Atlas n.d.).

\section{Physiological effects/actions of $\mathrm{CO}_{2}$}

$\mathrm{CO}_{2}$ causes a range of neurochemical, respiratory and vascular responses in both humans and non-humans (Woodbury \& Karler 1960). Low to moderate concentrations of $\mathrm{CO}_{2}$ (ranging from $5 \%$ to $35 \%$ ) cause changes in respiration rate (Thomas \& Spyer 2000), heart rate and blood pressure (Dripps \& Comroe 1947, Kety \& Schmidt 1947, Smith \& Harrap 1997), as well as HPA axis activity (Barbaccia et al. 1996). High concentrations of $\mathrm{CO}_{2}$ initially cause similar responses and may induce hyperventilation before respiratory and cardiac depression and subsequent failure (Martoft et al. 2003). The accumulation of $\mathrm{CO}_{2}$ also causes acidification of nasal mucosa (Anton et al. 1992, AVMA 2001). There is evidence that nonmyelinated nerve endings that sense chemicals (Thurauf et al. 1991) and $\mathrm{CO}_{2}$ sensitive olfactory receptors are present in the nasal mucosa of mammals, including rats (Coates 2001) and humans (Alvaro et al. 1993). The existence of these nerve endings 
and olfactory receptors indicate the ability to sense any pain that may be associated with $\mathrm{CO}_{2}$.

\section{Relevant human data}

There is evidence from human studies that inhalation of $\mathrm{CO}_{2}$ at various concentrations can cause pain and/or distress. For example, Danneman et al. (1997) asked 20 adult humans to take a full breath of $\mathrm{CO}_{2}$ at different concentrations ranging from 50\% to $100 \%$ and to score each concentration according to the level of discomfort. Results indicated that higher concentrations of $\mathrm{CO}_{2}$ were perceived to be increasingly noxious. Danneman's subjects used the following terms in reference to every concentration of $\mathrm{CO}_{2}$ tested: burning, tingling or prickling, and unpleasant (taste or odour); these terms were used more frequently at higher concentrations. Many described 100\% $\mathrm{CO}_{2}$ as piercing, stabbing, painful or causing the eyes to burn or water, and 18 out of 20 subjects indicated that they were unable to take a full breath of this concentration.

Dripps and Comroe (1947) found that $7-10 \% \mathrm{CO}_{2}$ in oxygen caused increases in pulse rate, respiratory rate, and blood pressure in male humans. Symptoms upon inhalation of $\mathrm{CO}_{2}$ included headache, dizziness and dyspnoea. Additional descriptions by the subjects included irritation of the nose, palpitation, faintness, 'generally uncomfortable,' muscle tremor and substernal pain. McArdle (1959) examined the effects of $30 \% \mathrm{CO}_{2}: 70 \% \mathrm{O}_{2}$ on the heart rate of humans and found no serious disturbance to cardiac function. However, $\mathrm{CO}_{2}$ caused hyperventilation, severe acidosis, a significant rise in arterial pressure, and was associated with an overall substantial degree of stress.

The ability of $\mathrm{CO}_{2}$ to induce pain in humans is underscored by the use of $\mathrm{CO}_{2}$ as a pain stimulus in humans. For example, Anton et al. (1992) examined pain thresholds induced by $\mathrm{CO}_{2}$ in the nasal mucosa in humans. A linear relationship was found between $\mathrm{CO}_{2}$ concentration and pain sensation. Average individual tolerance thresholds ranged from $40 \%$ to $55 \% \mathrm{CO}_{2}$.

\section{Animal studies regarding $\mathrm{CO}_{2}$ as a euthanasia agent: general information}

$\mathrm{CO}_{2}$ euthanasia occurs via administration of the inhalant gas in a sealed container, with the purpose of inducing unconsciousness and death (Britt 1986). One source of $\mathrm{CO}_{2}$ is 'dry ice,' but a pressurized cylinder of $\mathrm{CO}_{2}$ is now viewed by a number of international animal research oversight authorities as the only acceptable source (United Kingdom 1997). $\mathrm{CO}_{2}$ may be administered in the home cage or in a specialized compartment and may be used to kill individuals or small groups of animals.

Research regarding $\mathrm{CO}_{2}$ use in different species has examined several parameters such as blood pressure (Smith \& Harrap 1997), heart rate (Coenen et al. 1995, Smith \& Harrap 1997, Leach et al. 2002a,b), behaviour (e.g. Smith \& Harrap 1997, Leach et al. 2002a,b), times to anaesthesia and death (Blackshaw et al. 1988, Danneman et al. 1997, Kohler et al. 1999), EEG activity (Thurauf et al. 1991), histology (Britt 1986, Danneman et al. 1997) and blood pH (Hewett et al. 1993).

Procedural factors such as the $\mathrm{CO}_{2}$ concentration, flow rate and the presence of oxygen have also been included in the assessment of $\mathrm{CO}_{2}$. There are wide variations in the methods used, measurements taken and the resulting recommendations throughout the published literature; these factors limit the comparability of results, although some trends can be discerned. Discussions of $\mathrm{CO}_{2}$ euthanasia with various people working in laboratory animal medicine and care (e.g. veterinarians, vivarium directors, technicians) reveal that there are conflicting $\mathrm{CO}_{2}$ practices and recommendations within the animal research community. As one example, some institutions require that the euthanasia chamber be prefilled with $\mathrm{CO}_{2}$, while others prohibit the use of prefilled chambers because they appear to cause animal distress. 
Similar discrepancies in practice have also been noted in regards to concentration, flow rate and presence of oxygen.

\section{Pain and acute stress studies utilizing $\mathrm{CO}_{2}$} $\mathrm{CO}_{2}$ has been used as a pain and/or stress stimulus in animals. In some cases, the concentrations used correlate with concentrations used for $\mathrm{CO}_{2}$ euthanasia.

Thurauf et al. (1991) exposed rats to various concentrations of $\mathrm{CO}_{2}(0-90 \%)$ and measured evoked potentials in EEG recordings in order to determine the origin of negative mucosal potential (NMP - negative potential recorded from the respiratory mucosa following painful stimulation with $\mathrm{CO}_{2}$ ). Local anaesthetics eliminated NMPs and EEG cortical responses, signifying that the pain response had ceased. When no local anaesthetic was administered, the result was increased NMPs, indicating an increased nociceptive response.

Barbaccia et al. (1996) used $\mathrm{CO}_{2}$ to elicit a stress response in rats in order to examine the effects of acute stress on brain steroid concentrations and $\mathrm{GABA}_{\mathrm{A}}$ receptor function. A combination of $35 \% \mathrm{CO}_{2}$ and $65 \% \mathrm{O}_{2}$ inhaled from gas cylinders for one minute caused a sufficient stress response for the study. It was concluded that exposure to $\mathrm{CO}_{2}$ is correlated with an increase in various brain neuroactive steroid concentrations.

In sum, it is noteworthy that $\mathrm{CO}_{2}$ is used to induce pain and stress in animals, and the concentrations used in these studies are the same or similar to those used for anaesthesia and euthanasia.

\section{Effects of $\mathrm{CO}_{2}$ administration}

$\mathrm{CO}_{2}$ effects have been examined at various concentrations. A comparison of results illustrates concerns regarding pain and distress at concentrations ranging from $25 \%$ to $100 \%$. The results of a number of studies are discussed here and specifics are provided in Tables 1 and 2 for mice and rats.

Danneman et al. (1997) euthanized rats with various concentrations of $\mathrm{CO}_{2}$ (50-100\%) combined with oxygen via either prefilled or gradual induction (GI) chambers and found a number of adverse effects. Measures included time to recumbency, time to anaesthesia (shallow breathing or lack of response to toe pinch) and any clinical adverse effects. Adverse reactions, prior to death, included seizures, convulsive chewing, nasal haemorrhage, serosanguinous nasal discharge and excessive salivation. The frequency and severity of the adverse reactions were inversely related to $\mathrm{CO}_{2}$ concentration. It appears that these reactions occurred prior to or at onset of anaesthesia, but the publication does not make a clear distinction. Whether adverse reactions occur prior to or after unconsciousness is an important consideration and should be made clear in publications. Based on Danneman's results, it appears that lower concentrations (at least when considering $50 \% \mathrm{CO}_{2}$ and higher) cause increased incidence of adverse effects.

Ambrose et al. (2000) found that a concentration of $60 \% \mathrm{CO}_{2}$, supplied from a gas cylinder, caused many adverse effects in mice, whereas $30 \%$ was not as problematic. Simply introducing $\mathrm{CO}_{2}$ into the chamber caused behaviours such as increased locomotion, rearing, defaecation and urination. These behaviours are considered by Ambrose and others to be indicative of distress, but further investigation is needed for verification. Overall, the authors concluded that $60 \% \mathrm{CO}_{2}$ 'caused an undue amount of stress' (Ambrose et al. 2000).

Concentration, induction method and presence of oxygen with $\mathrm{CO}_{2}$ were examined in rats by Coenen et al. (1995). Gas cylinders were used and gas was humidified in all conditions. The authors reported four phases in each case of $\mathrm{CO}_{2}$ use: normal behaviour (phase I); continuous abnormal activity, excitation and agitation at a higher rate than normal (phase II); sagging of hindlegs and loss of body control (phase III); disappearance of muscle tone and head sinking (phase IV). Phase II was seen more frequently when $100 \% \mathrm{CO}_{2}$ was used. The same adverse signs were also observed at lower concentrations (without $\mathrm{O}_{2}$ ), but less frequently than in $100 \% \mathrm{CO}_{2}$. Animals experienced asphyxia (as evidenced by gasping with mouth open 


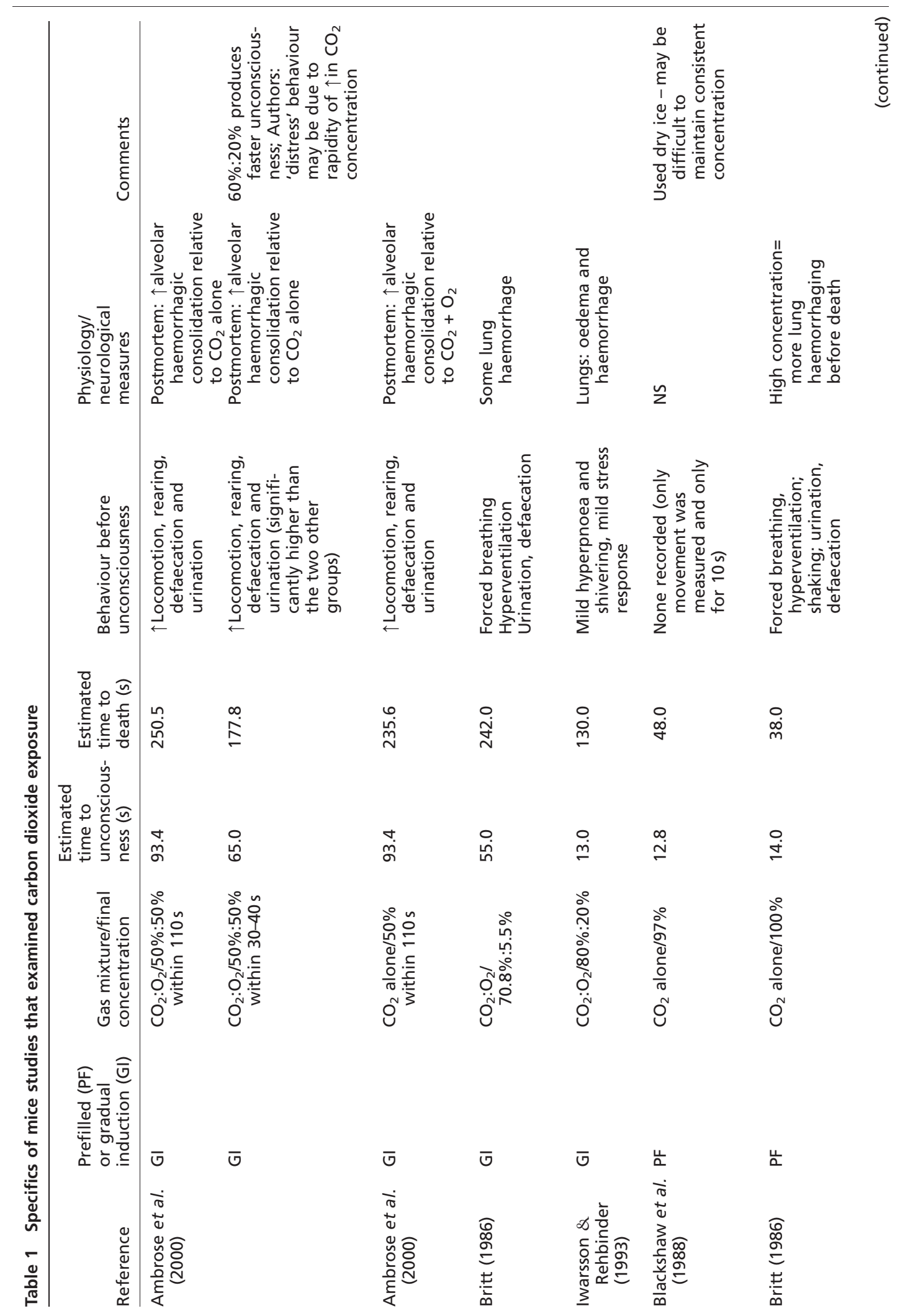




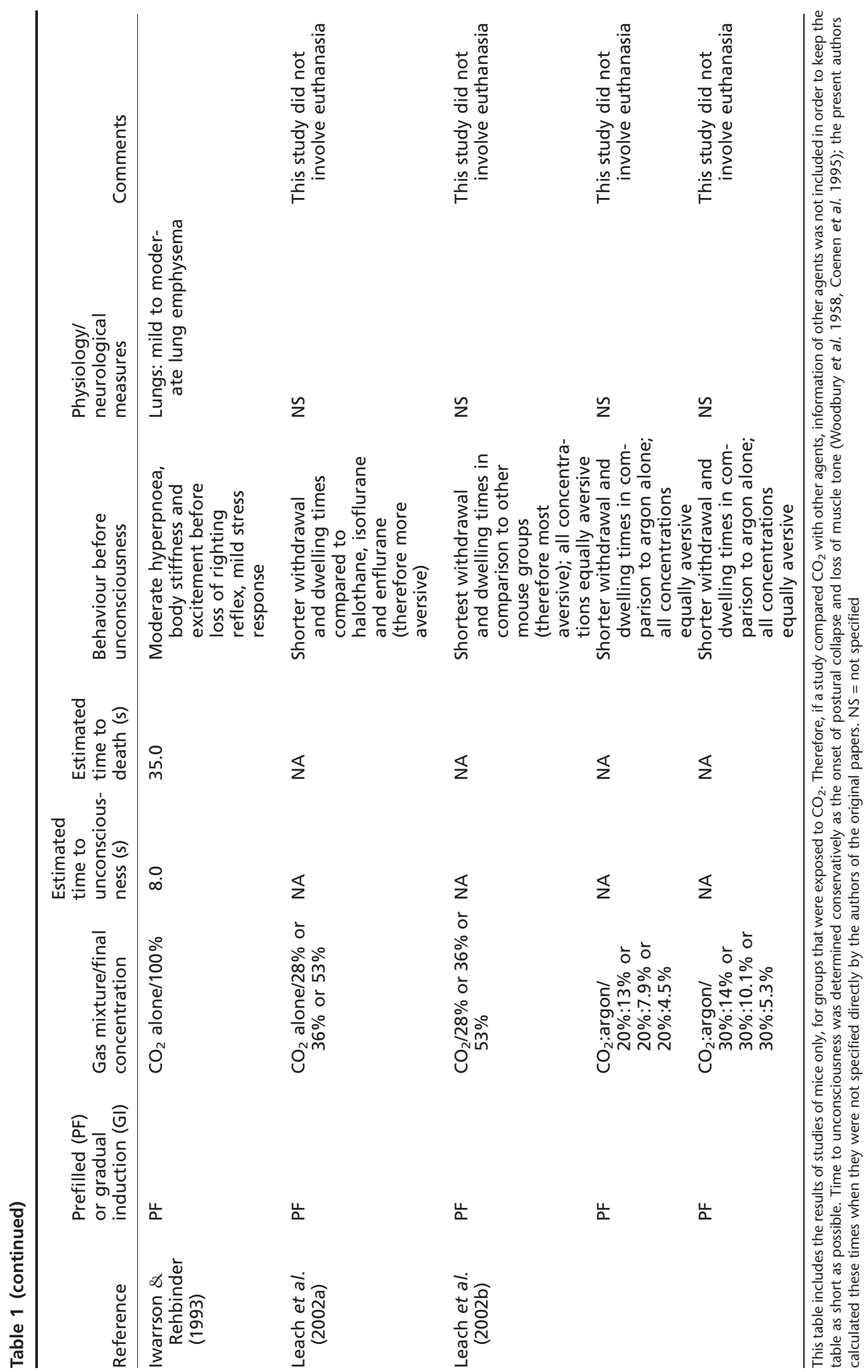




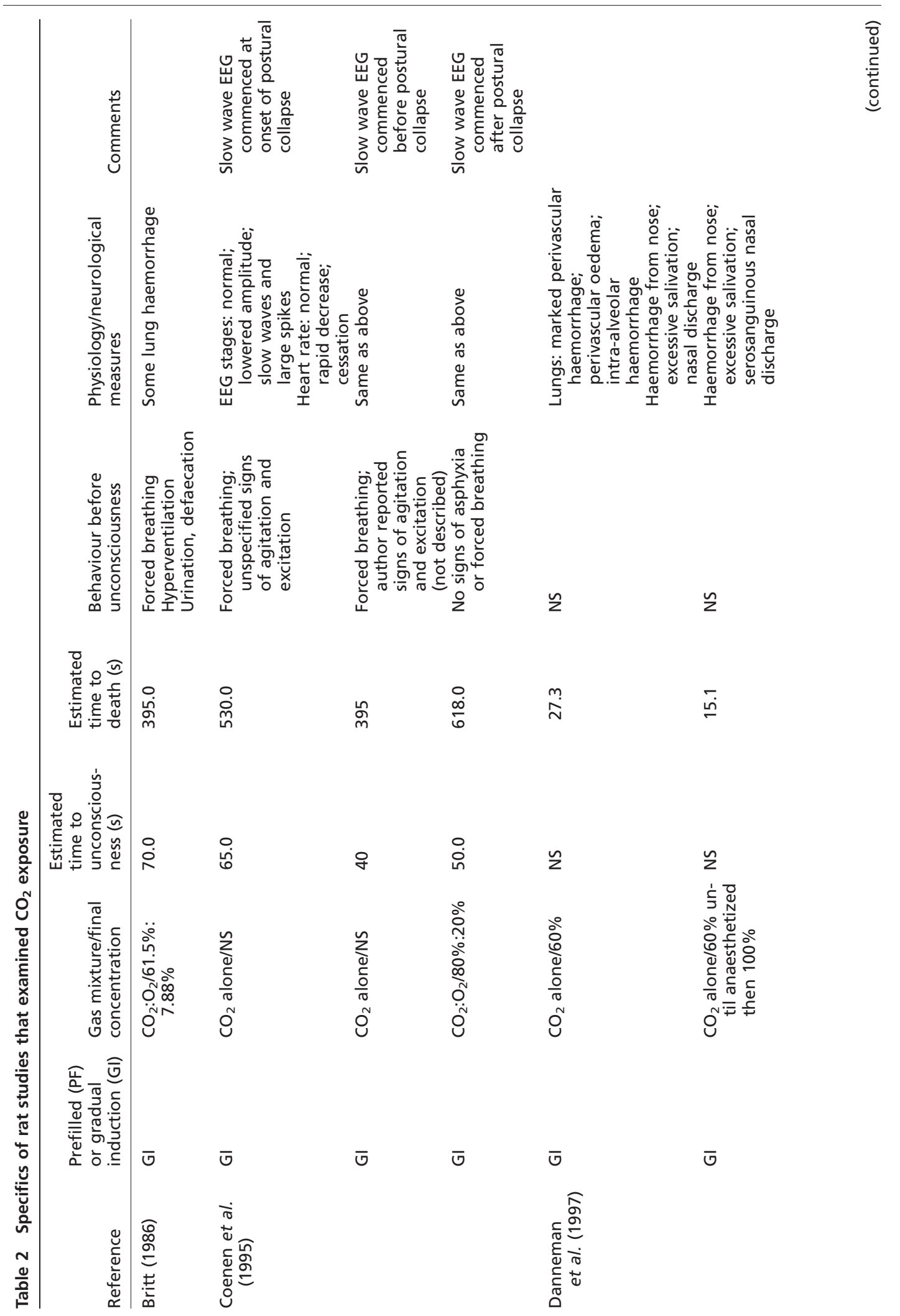




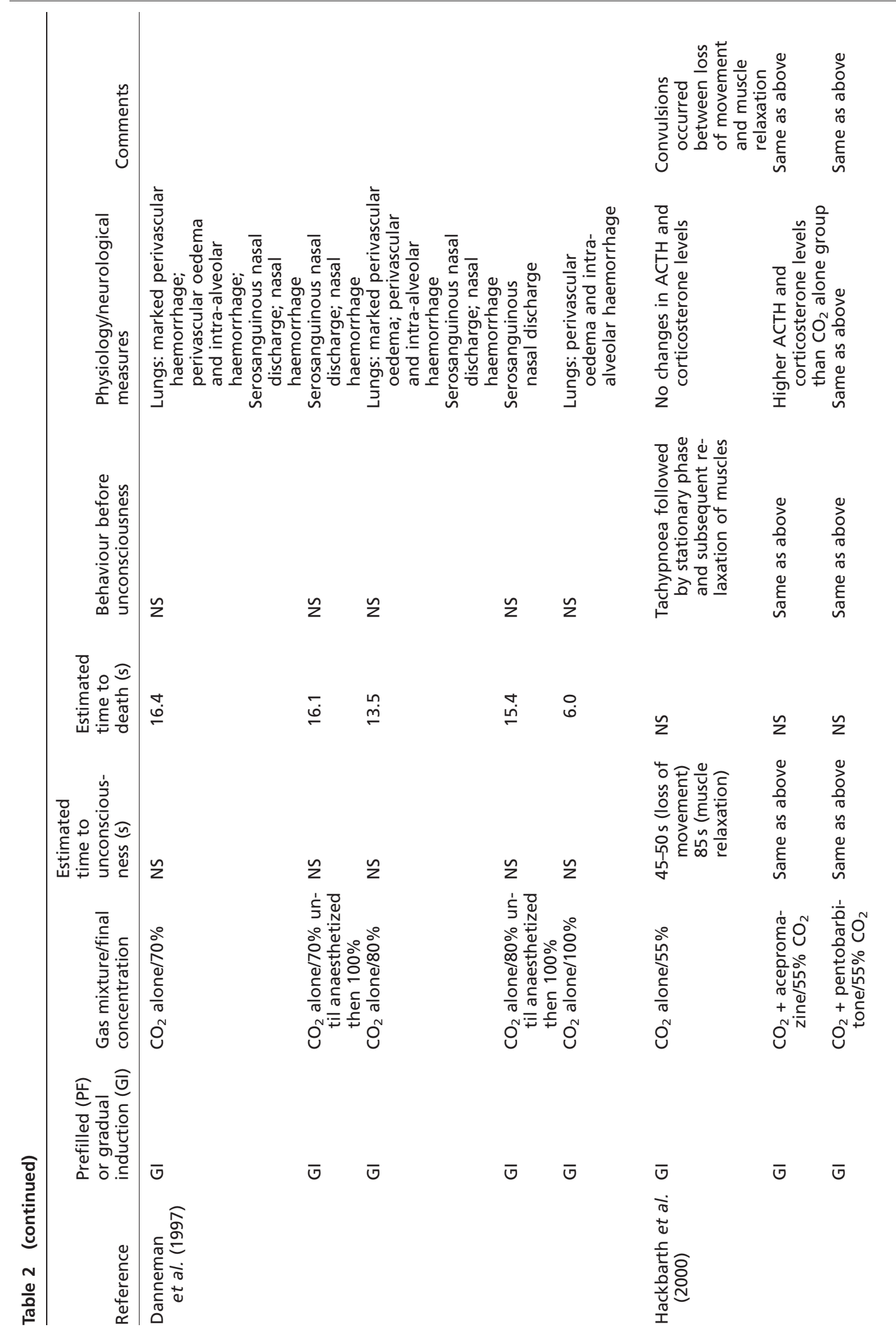



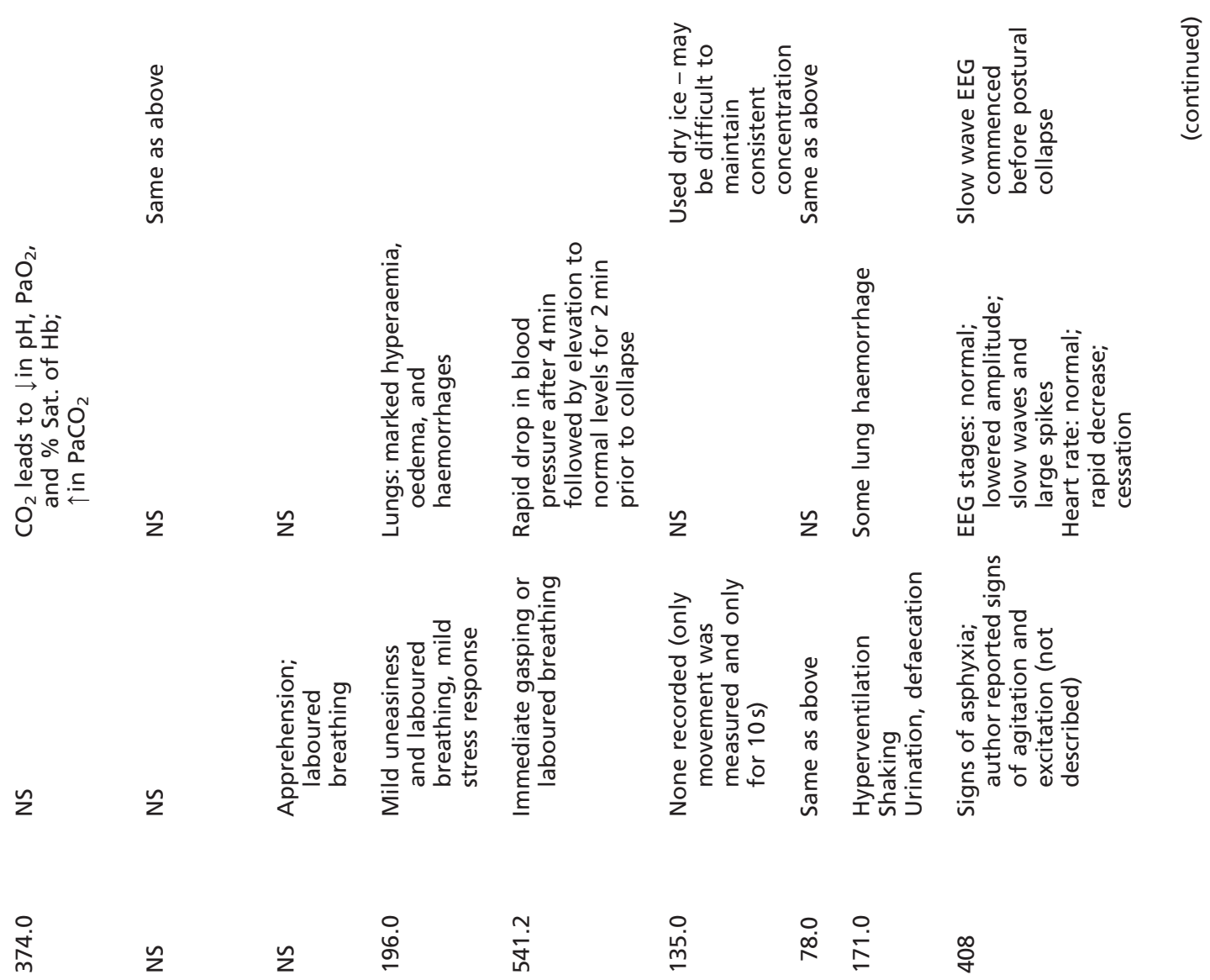

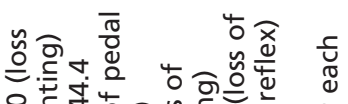

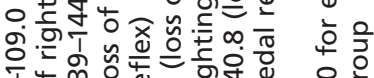

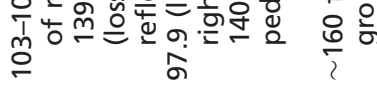

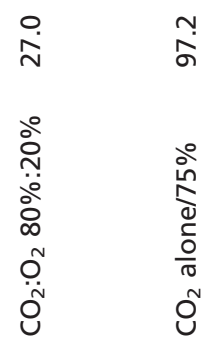

$\stackrel{\infty}{\sim} \quad \stackrel{\infty}{=} \stackrel{\circ}{\infty} \quad \stackrel{m}{\circ}$

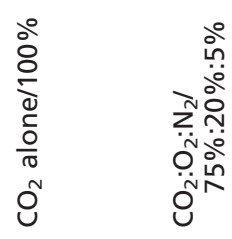

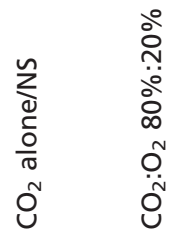

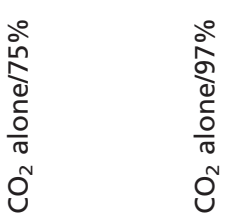

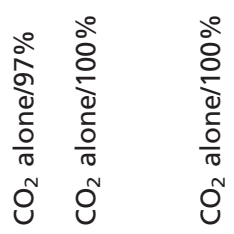

$\bar{\Xi}$

$\bar{\Xi}$

$\overline{5} \quad \overline{0}$

$\bar{\Xi}$

능

능

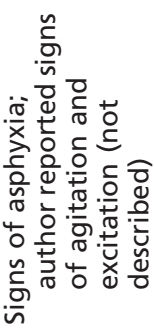

\&̊

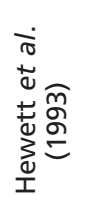

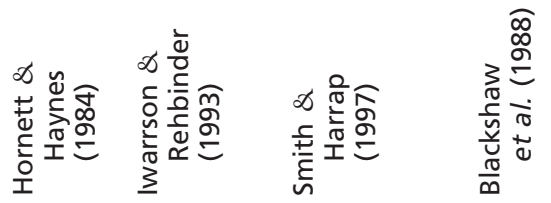

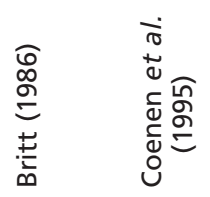




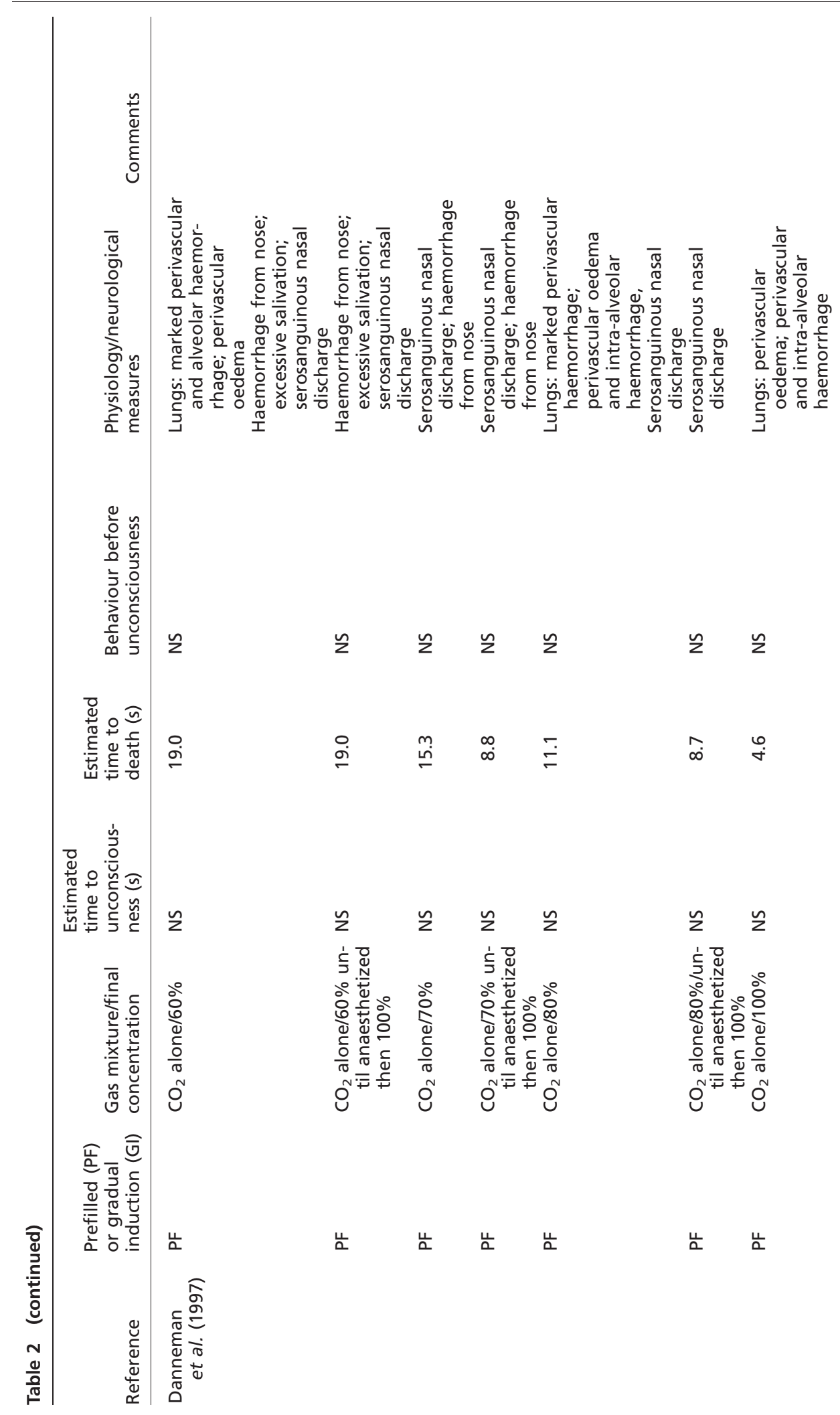



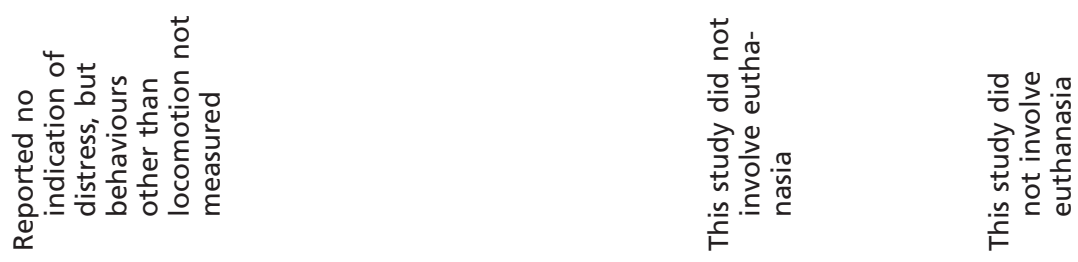

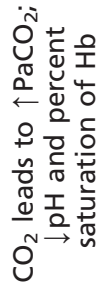

足

กั่

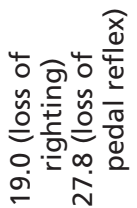

$\frac{\stackrel{0}{8}}{\frac{0}{0}} \frac{0}{0}$

㟔

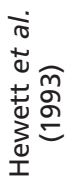

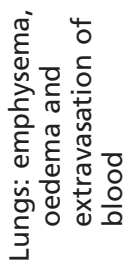
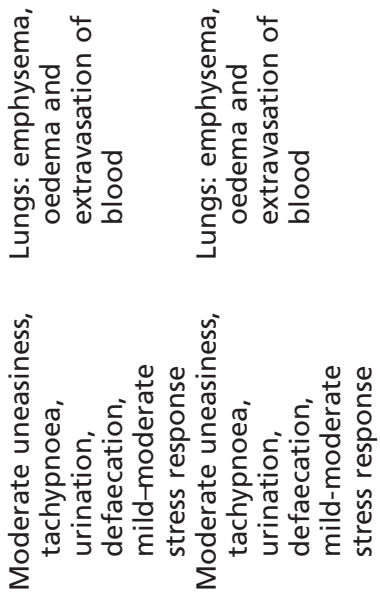

$\stackrel{ }{\underline{6}}$

$\stackrel{ }{m}$

$\stackrel{ }{m}$

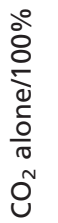

$\stackrel{0}{8}$
$\frac{0}{0}$
$\frac{1}{0}$
$\frac{0}{0}$

㟔

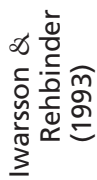

$气$

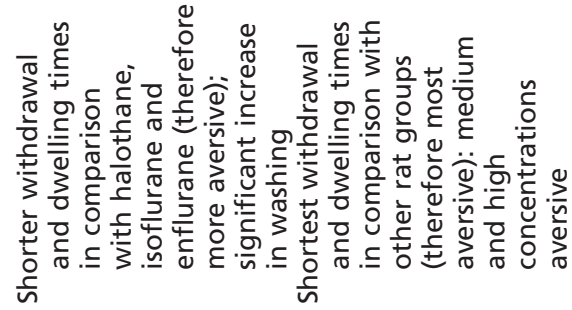

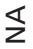

$\varangle$

$\varangle$

$\varangle$

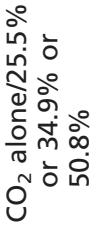

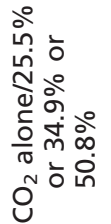

늠

늠 


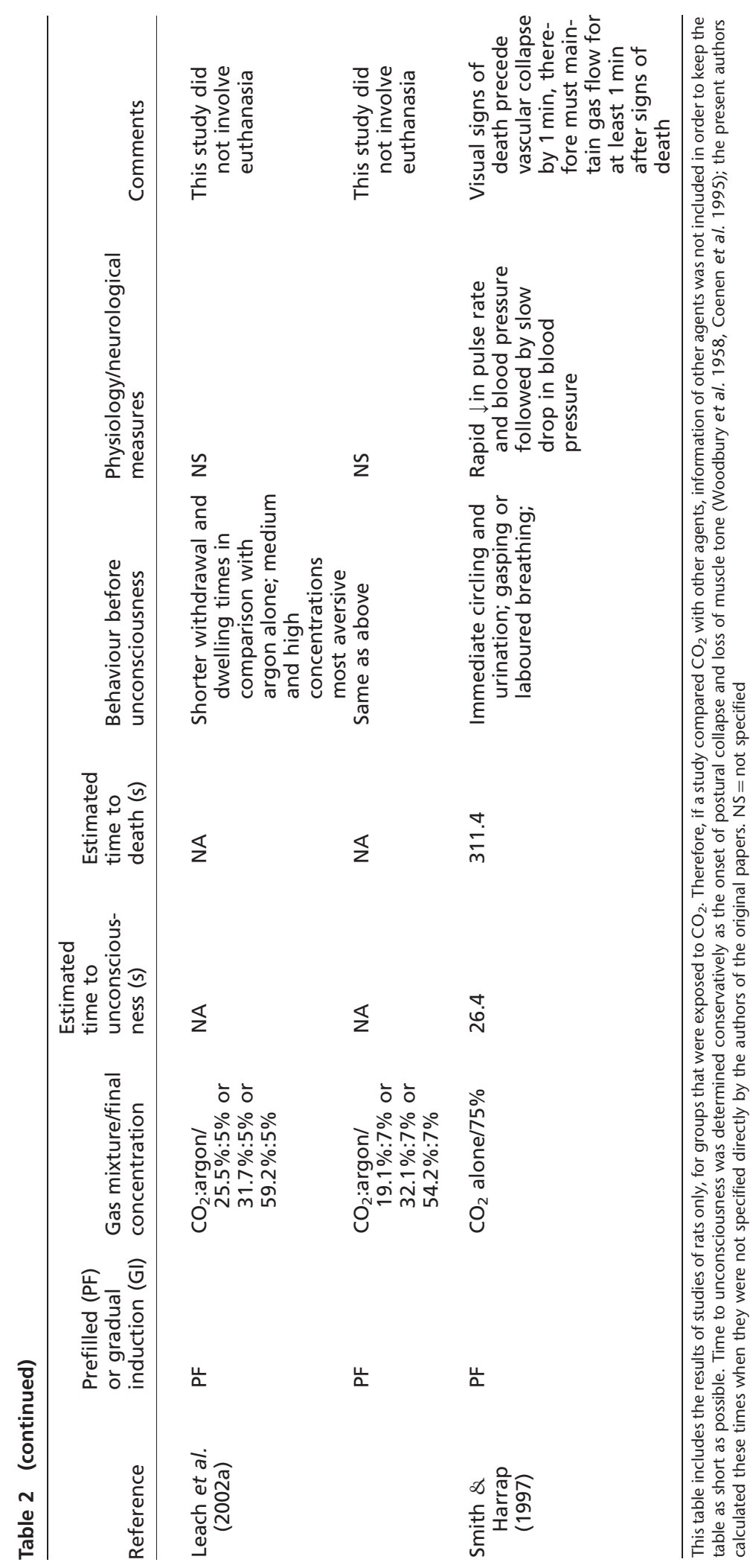


and head turned up and backward) in some conditions and those in the $100 \% \mathrm{CO}_{2}$ group showed most evidence of this behaviour. These results support the notion that higher concentrations of $\mathrm{CO}_{2}$ lead to increased adverse reactions; this is in contrast to the conclusion by Danneman et al. (1997) that lower concentrations of $\mathrm{CO}_{2}$ lead to increased incidence of adverse reactions.

Leach et al. (2002a,b) studied aversion to various gaseous euthanasia agents, including $\mathrm{CO}_{2}$, in rats and mice at low, medium and high concentrations. Measures of avoidance of, or preference for, different environments are well-established tools in the study of farm animal welfare. The animal's choice of environment is considered to reflect its priorities to access or avoid specific stimuli. In one study (Leach et al. 2002a), the agents were $\mathrm{CO}_{2}(25 \%, 35 \%, 50 \%)$ and argon $(93 \%$, $95 \%, 98 \%$ ), as well as two combinations of $\mathrm{CO}_{2}$ and argon. A second study (Leach et al. 2002b) compared halothane, isoflurane, enflurane and $\mathrm{CO}_{2}$ at low, medium and high concentrations. Aversion measures included time taken to initially withdraw from the test chamber, time spent in test chamber and frequency of entries and exits to and from the test chamber. Additional behavioural measurements indicative of aversion included washing, rearing, sniffing and excreting.

Overall, $\mathrm{CO}_{2}$, alone or in combination with argon, caused the highest degree of aversion in both rats and mice in both studies, with higher concentrations leading to significantly shorter withdrawal times (i.e. $0.6 \mathrm{~s}$ at highest concentration). In regards to the additional behavioural measurements examined, increase in frequency of 'washing' was the only clear trend, possibly the result of nasal irritation. The mice and rats differed in regards to response threshold, with mice having a lower threshold to $\mathrm{CO}_{2}$. Leach et al. concluded that $\mathrm{CO}_{2}$, either alone or in combination with argon, cannot be used humanely at any concentration and is therefore unacceptable as a euthanasia agent for laboratory rodents, particularly when more humane methods exist.
The findings of the studies discussed above demonstrate that $\mathrm{CO}_{2}$ causes adverse effects that lead to stress, and perhaps distress, at various concentrations ranging from $25 \%$ to $100 \%$.

A number of studies have examined the histological effects of $\mathrm{CO}_{2}$ and some results raise further concerns regarding pain and/or distress. Some physiological evidence of the effects of $\mathrm{CO}_{2}$ suggests that increasing physical trauma occurs when the extent of exposure to the inhalant gas increases.

Terminal $\mathrm{CO}_{2}$ inhalation has been shown to lead to alveolar extravasation (bleeding into the tissue) and pulmonary oedema (Danneman et al. 1997), haemorrhaging, lung oedema and emphysema (Iwarsson \& Rehbinder 1993), and degeneration of myocardial tissue and other organs (Iwarsson \& Rehbinder 1993). Britt (1986) reported increased pulmonary haemorrhaging in higher concentrations of $\mathrm{CO}_{2}$. However Danneman et al. (1997) found that the severity of pulmonary oedema and haemorrhage were inversely correlated with the concentration of inhaled $\mathrm{CO}_{2}$; this may be the result of increased time of exposure. Fawell et al. (1972) found oedema of perivascular connective tissue in the lungs of all rats subjected to $\mathrm{CO}_{2}$ euthanasia (concentration and flow rate were not indicated). An increased incidence of extravasation was considered to be related to the trauma of asphyxiation.

Only one recent study (Ambrose et al. 2000) has assessed the extent of oedema and alveolar consolidation (inflammatory induration of lung tissue) from samples taken immediately at the point of unconsciousness instead of following death. This study compared the use of $30 \% \mathrm{CO}_{2}$ with $30 \% \mathrm{CO}_{2}$ plus $20 \% \mathrm{O}_{2}$ in two strains of mice and it demonstrated greater alveolar consolidation in the $\mathrm{CO}_{2}+\mathrm{O}_{2}$ condition. This consolidation may have occurred just prior to loss of consciousness and led the authors to propose that the animal may not only demonstrate hyperventilation with exposure to $\mathrm{CO}_{2}+\mathrm{O}_{2}$, but may also experience a state similar to drowning while the animal is still conscious (Ambrose et al. 
2000). Danneman et al. (1997) also noted damage to the lungs and/or respiratory tract via observations of serious serosanguinous nasal discharge during exposure to $50 \% \mathrm{CO}_{2}$, but it is unclear whether this occurred when animals were still conscious. This evidence does raise the question of whether, without visible behavioural effects, the animal may experience a highly distressing state while still conscious, as oedema and haemorrhaging develop.

\section{Prefilled (PF) chamber versus gradual induction (GI)/times to anaesthesia and death}

The manner by which animals are exposed to $\mathrm{CO}_{2}$, PF chamber versus GI, has been examined fairly extensively. The results of these studies do not clearly indicate which method is preferred in regards to animal welfare, but these studies do demonstrate that both methods raise concerns in regards to animal welfare. Smith and Harrap (1997) compared GI (from $0 \%$ to $80 \% \mathrm{CO}_{2}: 3 \% \mathrm{O}_{2}$ ) versus $\mathrm{PF}\left(75 \% \mathrm{CO}_{2}: 3 \% \mathrm{O}_{2}\right)$ methods in rats. PF caused an immediate fall in blood pressure while GI caused increased blood pressure for the first $4 \mathrm{~min}$ and then a rapid decline. Additionally, time to unconsciousness was $30 \mathrm{~s}$ in PF subjects and $99 \mathrm{~s}$ in GI subjects; time to death was $5.4 \mathrm{~min}$ in $\mathrm{PF}$ subjects and $9 \mathrm{~min}$ in GI subjects. Although head-raising, urination, defaecation and gasping or laboured breathing were reported (behaviours were predetermined by the authors to be indicators of stress, pain, distress, anxiety and fear), the authors reported that $\mathrm{CO}_{2}$ caused few overt signs of distress in either group.

Hewett et al. (1993) examined the differences between PF and GI methods in rats at a final concentration of $100 \%$. Measurements included blood gas quantitation, and times to ataxia, immobility, loss of righting ability, loss of pedal reflex and anaesthesia (two consecutive negative pedal reflexes). The shortest amount of time to loss of pedal reflex was $28 \mathrm{~s}$, which occurred in the subjects exposed to the PF chamber. Loss of pedal reflex in the GI study occurred at $140 \mathrm{~s}$, or six times longer than the PF method. Overall, the authors reported that the animals' responses were not indicative of distress by either method. However, the study did not clearly indicate that any specific behaviours were looked for and therefore it is impossible to determine whether the animals were observed for anything other than ataxia and loss of pedal reflex.

Britt (1986) presented information on the humaneness of $\mathrm{CO}_{2}$ use based on a comparison of PF versus GI methods using rats and mice. Evaluations were based on types of behaviour, time spent in each activity, number of times activity was changed per unit of time, changes in breathing patterns with time and position in cabinet at loss of consciousness. Britt noted that time to collapse was shorter with PF, but PF caused more signs of distress. Abnormal behaviours (referred to by the author as signs of distress) included: shaking (frequent), moving in reverse, tail thrashing (uncommon) and increase in frequency of urination and defaecation. Urination and defaecation may result from the physiological effects of $\mathrm{CO}_{2}$ on the autonomic nervous system and conclusions regarding their use as indicators of stress should be cautious; however, they did arise in association with increased micturation, which may indicate disturbance or distress (Britt 1986). Behavioural responses varied between species and individuals. The author concluded that neither method is stress-free; however, he favoured GI.

Again, there is evidence from these studies that $\mathrm{CO}_{2}$ is associated with pain and distress, regardless of induction method. Overall, two studies concluded that neither method is problematic in regards to pain or distress (Hewett et al. 1993, Smith \& Harrap 1997), while one study (Britt 1986) indicated that prefilling leads to increased adverse reactions. One could conclude, therefore, that GI is preferred due to absence of adverse reactions, despite the fact that it may take longer to euthanize the animals.

\section{Presence of supplemental oxygen}

The use of oxygen supplementation in order to minimize pain and distress during $\mathrm{CO}_{2}$ 
use has also been a point of debate. Existing studies, again, provide conflicting results, depending on the effects examined.

Iwarsson and Rehbinder (1993) examined $\mathrm{CO}_{2}: \mathrm{O}_{2}$ mixtures for euthanasia of rats, mice and guineapigs. Animals were exposed to $\mathrm{CO}_{2}$ from a gas cylinder at either $100 \% \mathrm{CO}_{2}$ or $80 \% \mathrm{CO}_{2}: 20 \% \mathrm{O}_{2}$ via GI. The presence of oxygen doubled the amount of time to unconsciousness in rats and mice but, according to the authors, appeared to decrease distress. Stress response was determined by examining various behaviours, such as breathing, urination and defaecation. Postmortem examinations of lung tissue revealed that both methods generated adverse physiological reactions. It is not clear, however, if these changes in lung tissue occurred before or after unconsciousness.

As previously mentioned, Coenen et al. (1995) reported that there were four phases in the response to $\mathrm{CO}_{2}$ inhalation in rats. The phase of continuous abnormal activity (excitation and agitation) was completely absent in the presence of oxygen. While $100 \% \mathrm{CO}_{2}$ produced the shortest time to death, the authors concluded that the presence of added oxygen produced a longer time to death but with a reduction of adverse effects. Therefore, adding oxygen was considered to be the preferred method. However, the difference in concentrations of $\mathrm{CO}_{2}$, and not the use of supplemental oxygen, could be the cause of these results.

The results from Ambrose et al. (2000), however, appear to conflict with those of Coenen et al. (1995). Ambrose et al. compared $30 \%$ chamber volume per minute of $\mathrm{CO}_{2}$ with and without supplemental oxygen. There were no behavioural differences observed between the two conditions and presence of oxygen was found to increase alveolar consolidation. The authors concluded that '[a]s haemorrhage is likely to be stressful to the mice by inducing a feeling of 'drowning', any alveolar consolidation above basal level indicates potential poor welfare' and that addition of $20 \%$ chamber volume per minute of $\mathrm{O}_{2}$ is not recommended as a refinement to $\mathrm{CO}_{2}$ euthanasia. The reason for the conflict with
Coenen et al. (1995) results is unclear, but neither author described the behaviours that were assessed in order to determine aversion; differences in behavioural data collection and analysis could explain differences between results of this as well as other studies.

\section{Time to and measurements of unconsciousness}

It is important to determine the point at which unconsciousness occurs in order to clearly identify whether adverse effects occur prior to or following unconsciousness. Experienced veterinary clinicians have indicated that anaesthesia sets in so quickly when $\mathrm{CO}_{2}$ is used that there is not sufficient time for the animals to experience significant pain and distress. However, a review of the literature finds that times to unconsciousness vary greatly when using recommended methods. As discussed, many authors use different terminology, such as: anaesthesia, collapse, recumbency, unconsciousness and immobility. The following are observations of rats exposed to the AVMA-recommended condition of prefilling the chamber with $70 \%$ $\mathrm{CO}_{2}$ : Danneman et al. (1997) recorded that anaesthesia (onset of slow, shallow breathing and loss of response to toe pinch with haemostats) occurred at an average of $4.01 \mathrm{~min} ;$ Mischler et al. (1994) recorded anaesthesia ('appeared comatose, exhibited muscle flaccidity and were unresponsive to deep pressure applied to the tail and/or hindpaw') within a maximum of $10 \mathrm{~s}$; and Smith and Harrap (1997) reported 'loss of recumbency' at an average of $26.6 \mathrm{~s}$. What could account for this variability? Some possibilities are variations in gas concentrations, sample sizes, methods and equipment used, condition of the animals, and how unconsciousness was actually measured.

Although many papers have described the onset of ataxia as symptomatic of the onset of the effects of $\mathrm{CO}_{2}$ (Hewett et al. 1993, Coenen et al. 1995, Danneman et al. 1997), it is not clear whether ataxia itself is distressing. It is possible that the inability to behave adaptively or complete purposeful locomotion might be unpleasant. Further 
research is needed to assess whether an ataxic state is aversive.

Overall, as the inhaled $\mathrm{CO}_{2}$ concentration increases, both time to unconsciousness (Britt 1986, Danneman et al. 1997, Ambrose et a1. 2000, Leach et al. 2002a,b) and time to death (Britt 1986, Ambrose et al. 2000) decrease, while the addition of oxygen to the inhalant gases increases time to death (Coenen et al. 1995). Additional details are provided in Figure 1 and Tables 1 and 2. It would appear that if time to unconsciousness were the only criteria influencing distress, higher concentrations of $\mathrm{CO}_{2}$ would be beneficial. However, before such a decision is made, it is important to determine what the intensity of such distress might be, while also taking into consideration reaction of humans to high concentrations of $\mathrm{CO}_{2}$.

\section{Summary}

The literature demonstrates that $\mathrm{CO}_{2}$ is painful and/or distressful in humans at concentrations ranging from $7 \%$ to $100 \%$, and that there is sufficient evidence that $\mathrm{CO}_{2}$ likely causes pain and distress in animals. Table 3 summarizes the incidence

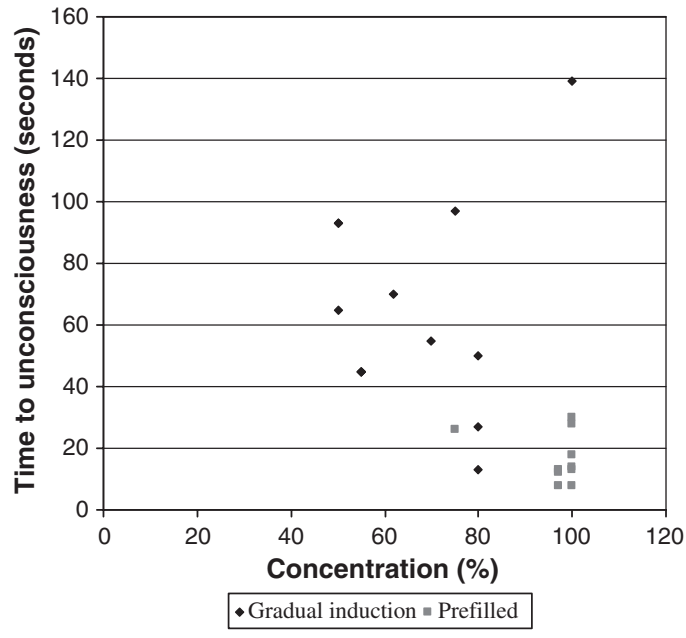

Figure 1 Effects of concentration on times to unconsciousness: gradual induction and prefilled chamber

of adverse reactions in the literature reviewed here. Adverse reactions to $\mathrm{CO}_{2}$ in species other than those discussed in this review, including cats (Simonsen et al. 1981), dogs (Eisele et al. 1967) and guineapigs (Iwarsson \& Rehbinder 1993), can be found in the scientific literature. In summary, the human and animal literature

Table 3 Comparison of publications reviewed for this paper: those that reported adverse effects and those that reported no adverse effects in response to carbon dioxide

\begin{tabular}{|c|c|c|}
\hline Author (year) & No adverse effects reported & Adverse effects reported \\
\hline $\begin{array}{l}\text { Ambrose et al. (2000) } \\
\text { Barbaccia et al. (1996) } \\
\text { Blackshaw et al. (1988) } \\
\text { Britt (1986) } \\
\text { Coenen et al. (1995) } \\
\text { Danneman et al. (1997) } \\
\text { Fawell et al. (1972) } \\
\text { Hackbarth et al. (2000) } \\
\text { Hewett et al. (1993) } \\
\text { Hornett \& Haynes (1984) } \\
\text { Hoenderken (1983) } \\
\text { Iwarsson \& Rehbinder (1993) } \\
\text { Jongman et al. (2000) } \\
\text { Leach et al. (2002a) } \\
\text { Leach et al. (2002b) } \\
\text { Raj \& Gregory (1994) } \\
\text { Raj \& Gregory (1995) } \\
\text { Raj \& Gregory (1996) } \\
\text { Robb et al. (2000) } \\
\text { Smith \& Harrap (1997) } \\
\text { Thurauf et al. (1991) }\end{array}$ & $\begin{array}{l}\sqrt{ } \\
\sqrt{ } \\
\sqrt{ } \\
\sqrt{ }\end{array}$ & $\begin{array}{l}\sqrt{ } \\
\sqrt{ } \\
\sqrt{ } \\
\sqrt{ } \\
\sqrt{ } \\
\sqrt{ } \\
\sqrt{ } \\
\sqrt[V]{ } \\
\sqrt[V]{ }\end{array}$ \\
\hline
\end{tabular}


signals that the use of $\mathrm{CO}_{2}$ may be problematic.

\section{Rodent studies that compare the use of $\mathrm{CO}_{2}$ alone with other euthanasia methods}

A fair amount of the published data on $\mathrm{CO}_{2}$ stems from studies that compared $\mathrm{CO}_{2}$ with other euthanasia methods. $\mathrm{CO}_{2}$ concentration, induction method and presence of oxygen remain potentially confounding factors. The studies discussed here conclude that $\mathrm{CO}_{2}$ is a preferable euthanasia agent for rodents in comparison to ether, chloroform, nitrogen, and that the use of anaesthesia with pentobarbital or sedation prior to induction with $\mathrm{CO}_{2}$ has no particular benefits.

Blackshaw et al. (1988) compared $\mathrm{CO}_{2}$, ether and chloroform in rats, mice and chickens. Dry ice was used to generate $97 \% \mathrm{CO}_{2}$ in a prefilled chamber. Time to collapse and death were shortest with $\mathrm{CO}_{2}$ for all three species in comparison with ether and chloroform. Adverse behavioural signs to $\mathrm{CO}_{2}$ were not observed, except for wing flapping in chickens.

Arguing that the shortest time to death is preferable when choosing a euthanasia agent (while also taking behaviour prior to unconsciousness into consideration), the authors concluded that $\mathrm{CO}_{2}$ was the preferred agent for rats and mice, but not chickens. One potential problem with this study is that the behaviours observed focused on the animal's movement and did not include other behaviours that may be indicative of stress (e.g. urination and defaecation) that were observed in other $\mathrm{CO}_{2}$ studies.

Hornett and Haynes (1984) compared $\mathrm{CO}_{2}$ and nitrogen in rats and concluded that $\mathrm{CO}_{2}$ was the preferred euthanasia method. $\mathrm{CO}_{2}$ from a gas cylinder was gradually induced and behaviours measured included perceived signs of fear (behaviours were not specified) and oxygen deprivation, as well as laboured breathing, loss of co-ordination and balance, collapse (correlated with unconsciousness) and respiratory arrest. Overall, the rats had an extreme response to nitrogen including panic, attempts to escape and convulsions, while $\mathrm{CO}_{2}$ caused increased 'nasal movement' and a stage of laboured breathing. The authors concluded that $\mathrm{CO}_{2}$ at $19.5 \%$ chamber volume per minute 'achieved a quiet delivery into unconsciousness'.

Finally, Hackbarth et al. (2000) examined whether sedation (acepromazine in chopped meat) or anaesthesia (injection of sodium pentobarbitone) prior to the use of $\mathrm{CO}_{2}$ would decrease the stress-induced effects of $\mathrm{CO}_{2}$ euthanasia. Rats were subjected to one of four conditions followed by $\mathrm{CO}_{2}$ : meat with acepromazine, meat without acepromazine, injection with pentobarbitone or injection with saline. Behavioural observations were recorded and adrenocorticotrophic hormone (ACTH), glucose and corticosterone measurements were taken at various times after $\mathrm{CO}_{2}$ induction began. No group exhibited behavioural signs of pain or distress. Glucose and corticosterone levels did not differ between the groups. ACTH was higher in the subjects given injections in comparison with those given oral treatments (assumed to be a result of handling stress). Given the relative absence of effects of sedation and anaesthesia, the authors concluded that '... euthanasia with $\mathrm{CO}_{2}$ [without prior sedation or anesthetization] is in concordance with animal welfare as it is rapid and does not cause distress in the animal and therefore can be recommended as "humane" ".

These studies do not show evidence of distress as some of the previously discussed studies have. Again, this may be a result of the behaviours examined and differences between studies in interpreting behaviour and other measures. Differences in behaviour are important to recognize because each individual, as well as each species, has a particular coping strategy and pain threshold (Leach et al. 2002b).

\section{Literature on stunning for slaughter}

The use of $\mathrm{CO}_{2}$ for stunning prior to slaughter has been examined in a number of studies with different species. Overall, many studies found that $\mathrm{CO}_{2}$ is aversive, as demonstrated by avoidance by the animals. 
Raj and Gregory $(1995,1996)$ compared the use of argon $(90 \%)$ and $\mathrm{CO}_{2}(30 \%$ or $90 \%)$ for stunning in pigs and found high concentrations of $\mathrm{CO}_{2}$ to be highly aversive. Aversion was assessed from the pigs' reluctance to enter or remain in the gaseous atmospheres for a reward of apples. When $90 \% \mathrm{CO}_{2}$ was in the box, the pigs immediately withdrew their heads, repeatedly attempted to feed, but withdrew their heads when they began to hyperventilate. The following day, three out of six pigs hesitated to enter the box. It was concluded that high concentrations $(90 \%)$ of $\mathrm{CO}_{2}$ were aversive to the majority of pigs $(88 \%)$ and that they would not attempt to get the apples, even after $24 \mathrm{~h}$ of fasting. By contrast, pigs did not demonstrate aversion to the presence of argon and the majority did not demonstrate aversion to $30 \% \mathrm{CO}_{2}$ in air (Raj \& Gregory 1995). Since the design of the study allowed for escape and did not force the animals to be exposed to the gas, distress was not examined. However, the study does demonstrate that when given a choice, pigs will avoid high concentrations of $\mathrm{CO}_{2}$. Comparable results were found in a similar experiment on turkeys (Raj \& Gregory 1994).

A second study (Raj \& Gregory 1996) examined the severity of respiratory distress when pigs were placed in a well of various concentrations of argon with or without oxygen and/or $\mathrm{CO}_{2}$ in air. Respiratory distress was scored and it was found that argon with $2 \%$ oxygen induced minimal respiratory distress, while the combination of $30 \% \mathrm{CO}_{2}$ and argon with residual oxygen induced moderate distress, and all concentrations of $\mathrm{CO}_{2}$ in air 'induced severe respiratory distress in the pigs' (Raj \& Gregory 1996).

Hoenderken (1983) compared $\mathrm{CO}_{2}$ and electrical stunning methods in pigs and also found $\mathrm{CO}_{2}$ to be aversive. Behaviours (specific behaviours were not indicated) and EEG were recorded while $\mathrm{CO}_{2}$ was used; specific concentrations and induction methods were not clearly indicated in the publication. It was found that pigs show signs of excitation after $12 \mathrm{~s}$ of exposure to $\mathrm{CO}_{2}$ and this excitation lasts $26 \mathrm{~s}$ on average (isoelectric EEG was recorded at $56 \mathrm{~s}$ ). The author concluded that there is a long period of excitement during $\mathrm{CO}_{2}$ exposure.

Jongman et al. (2000), however, found shock with an electric prod to be more aversive than $90 \% \mathrm{CO}_{2}$ based on the pigs' reluctance and time to enter the treatment area following previous exposure to the stimuli. Behaviour other than time to enter treatment area was not measured in this study.

Finally, four slaughter methods (exsanguination without stunning, $\mathrm{CO}_{2}$ stunning followed by gill cutting, percussive stunning and spiking) were compared in salmon; behaviour and visual evoked response to a flash of light (lack of response $=$ good indicator of brain failure) were examined (Robb et al. 2000). $\mathrm{CO}_{2}$ caused the fish to shake their heads and tails vigorously for $2 \mathrm{~min}$, which resumed again after gill cutting. Loss of visual evoked responses also took much longer with exsanguination and $\mathrm{CO}_{2}$. Overall, the authors recommended the use of stunning or spiking over exsanguination or $\mathrm{CO}_{2}$.

These studies, overall, demonstrate that $\mathrm{CO}_{2}$ stunning for slaughter causes adverse effects and is avoided when the animals are provided with the opportunity to do so. In some instances, as described by Jongman et al. (2000), the animals will choose $\mathrm{CO}_{2}$ over other methods; however, this does not indicate that $\mathrm{CO}_{2}$ is the preferred of all available methods.

\section{Pain and distress: considerations}

Pain is considered to be the experience of an unpleasant sensory and emotional state that arises from central perception of nociception mechanisms in response to actual or potential tissue damage (International Association for the Study of Pain 1979). Distress is primarily considered to encompass both physiological and psychological states, and may be observed through physiological and behavioural responses which indicate that the animal is experiencing stimuli as noxious and from which the animal is motivated to avoid or withdraw (Dawkins 1990, Rolls 1999).

There are a range of measures of physiological function and behaviour that 
may be used to determine whether an animal is in a state of distress. These include heart rate, blood pressure, circulating free cortisol, measures of behavioural aversion or avoidance and behavioural correlates of pain or distress (Appleby \& Hughes 1997, Mason et al. 2001). A range of authors have measured a variety of behavioural and physiological responses as indicators of pain and distress in studies of $\mathrm{CO}_{2}$, such as behavioural signs of asphyxia (Coenen et al. 1995), hyperventilation (e.g. Britt 1986, Kohler et al. 1999), escape behaviours (Britt 1986, Leach et al. 2002a,b), tail thrashing (Britt 1986), disturbance behaviours such as washing (Britt 1986) and physiological signs of nociception (Anton et al. 1992). The interpretation of such behavioural measures can be difficult if the association between the behaviour and an underlying state has not been validated, or where behaviours are poorly described, or where quantitative measures are not used and the reliability of observational recordings confirmed (see Martin and Bateson (1993) for a discussion). Further complications arise as some authors may not have been consistent in measuring particular behaviours, or may have drawn different conclusions regarding similar behavioural phenomena (e.g. Britt 1986, Blackshaw et al. 1988, Hewett et al. 1993, Danneman et al. 1997).

As seen in Tables 1 and 2, the current evidence regarding $\mathrm{CO}_{2}$ inhalation and pain and distress is based on studies using a diverse range of exposure methods, gas concentrations and mixtures, as well as species and genetic strains. The types of variables measured are inconsistent, and often physiological and behavioural data have not been collected from the same experiment. For behavioural data to be meaningful, rigorous ethological techniques are required, including organized sampling methods, quantifiable measurement and good quality objective description, allowing for future interpretation and replication (Martin \& Bateson 1993). Behaviours interpreted as indicating underlying physiological changes should be validated where possible. The increasing sophistication of techniques from animal welfare science, such as measures of aversion, are valuable tools for understanding the animal's priorities and choices in light of exposure to environmental stimuli. The use of control animals (where $\mathrm{CO}_{2}$ is not present) would also be useful to indicate the extent to which the behaviours and physiological responses observed in previous studies arise from the novelty, unfamiliarity or mixing with unfamiliar conspecifics.

Despite some of the problems with the data in the above studies, it can be concluded that the information available is more than sufficient to raise concerns about the pain and distress associated with $\mathrm{CO}_{2}$ euthanasia.

\section{Existing guidelines for euthanasia}

Various organizations and agencies such as the AVMA (2001), CCAC (1993), the European Commission (1996, 1997), the Australia and New Zealand Council for the Care of Animals in Research and Teaching (ANZCCART 2001), the UK Home Office (1997b) and the Universities Federation for Animal Welfare (UFAW 1986) provide guidelines on euthanasia. These guidelines provide conflicting recommendations in regards to $\mathrm{CO}_{2}$ euthanasia, specifically the optimal concentrations, rates of induction and sources of $\mathrm{CO}_{2}$.

In July 2002, the Office of Laboratory Animal Welfare (OLAW) of the US National Institutes of Health published a guidance notice that high concentrations of $\mathrm{CO}_{2}$ may be distressful to some species and therefore prefilling the chamber is only recommended when such use has not been shown to cause distress (OLAW 2002). This recommendation conflicts with the AVMA guidelines that suggest using a prefilled chamber, illustrating the continuing confusion regarding $\mathrm{CO}_{2}$ use.

\section{Discussion of $\mathrm{CO}_{2}$ use}

The evidence that $\mathrm{CO}_{2}$ causes pain and distress in both humans and animals can be summarized as follows.

(1) $\mathrm{CO}_{2}$ has been used in animals as a painful stimulus (Thurauf et al. 1991), 
at a concentration that is typically used for euthanasia, and in studies to elicit an acute stress response (Barbaccia et al. 1996); this supports the claim that $\mathrm{CO}_{2}$ causes pain and distress in rodents.

(2) Although high concentrations of $\mathrm{CO}_{2}$ have been found to cause more pain and distress in comparison with low concentrations, pain and distress have also been reported at low concentrations, such as $20 \% \mathrm{CO}_{2}$ in pigs (Raj \& Gregory 1996 ) and $25 \%$ in rats and mice (Leach et al. 2002a,b). Reported findings that there is increased noxiousness with increased concentrations of $\mathrm{CO}_{2}$ are of concern because some literature and most available euthanasia guidelines recommend the use of higher concentrations of $\mathrm{CO}_{2}$ due to its shorter time to recumbency, anaesthesia and euthanasia.

(3) According to published findings and anecdotal reports, GI and prefilled euthanasia chambers both lead to concerns about pain and distress.

(4) The histological effects of $\mathrm{CO}_{2}$ on lungs, heart and other organs, including oedema and haemorrhage, raise concerns about animal distress.

Policies of the OECD and individual countries indicate that if a procedure causes pain and distress in humans, it must be considered to cause pain and distress in animals (US Public Health Service Policy also indicates 'in the absence of evidence to the contrary'). The evidence that $\mathrm{CO}_{2}$ elicits a painful response in humans (Dripps \& Comroe 1947, McArdle 1959, Anton et al. 1992, Hummel et al. 1994, Danneman et al. 1997) is very strong. Therefore, these policies require that $\mathrm{CO}_{2}$ use should be considered painful and distressful in animals.

\section{Alternatives to use of $\mathrm{CO}_{2}$}

Discontinuing use of $\mathrm{CO}_{2}$ alone as a euthanasia agent is unlikely to happen soon because it is so widely used, but there are some reasonable alternatives.

\section{Pre-anaesthetic followed by $\mathrm{CO}_{2}$}

The use of a pre-anaesthetic to induce unconsciousness prior to induction of $\mathrm{CO}_{2}$ for euthanasia should be considered.

Halothane was found to be the least aversive by Leach et al. (2002b) when distress associated with induction of halothane, isoflurane, enflurane and $\mathrm{CO}_{2}$ were compared.

Halothane, isoflurane and enflurane were found to be more aversive than air, but were significantly less aversive than $\mathrm{CO}_{2}$.

Use of pre-anaesthetic agents with $\mathrm{CO}_{2}$ should be acceptable for the euthanasia of large numbers of animals not involved in research protocols or for the euthanasia of small numbers of animals where the effect of the anaesthetic gas is not a problem. Where the research protocol calls for tissues unaffected by anaesthetics, decapitation may be the best method for small numbers of rats or mice. However, this method is still questioned because of the debate over the meaning of the EEG trace following decapitation and also because of the high chance for error due to inadequate operator training or guillotine maintenance.

Inhalational gas agents are particularly advantageous because they require minimal handling of the animals and larger numbers of animals can be euthanized simultaneously. As Hackbarth et al. (2000) report, an injectable pre-anaesthetic can cause a handling-induced stress response.

One concern about the use of volatile anaesthetics is exposure of personnel to the gas. However, there are portable scavenging units that would allow for safe use of both a pre-anaesthetic and $\mathrm{CO}_{2}$. The European Commission recommendations for euthanasia indicate that halothane, enflurane and isoflurane 'are all acceptable agents with appropriate gas scavenging apparatus'.

\section{Argon}

Argon, an odourless, inert gas that is nonflammable and non-explosive (AVMA 2001), is another option for euthanasia that might be an improvement over the use of $\mathrm{CO}_{2}$. Leach et al. (2002b) found argon to be much less aversive to rats and mice in comparison to $\mathrm{CO}_{2}$, although all examined concen- 
trations of argon (ranging from 25\% to 53\%) caused a degree of aversion in comparison to air. Raj and Gregory (1995) found no aversion to argon (90\%) in pigs. The AVMA (2001) considers argon to be only conditionally acceptable, but this recommendation did not cite the scientific literature. The existing literature, however, does generally demonstrate that argon is preferable to $\mathrm{CO}_{2}$ in regards to animal welfare. The Farm Animal Welfare Council (2003), for example, indicates that argon is less aversive in pigs in comparison to $\mathrm{CO}_{2}$. The council also expresses support for additional research in order to determine how to best use argon for euthanasia purposes.

Lawson et al. (2003) compared the use of $\mathrm{CO}_{2}$, nitrogen and argon for euthanasia and found that $\mathrm{CO}_{2}$ induced 'apparent unconsciousness' within $40 \mathrm{~s}$ and death within approximately $3 \mathrm{~min}$, and argon had similar effects (unconsciousness at $55 \mathrm{~s}$ and death at $4 \mathrm{~min}$ ). However, $\mathrm{CO}_{2}$ caused a rapid and significant increase in blood pressure (measured by radio-telemetry), while argon and nitrogen caused muscle rigidity and spasms. In this case, the authors concluded that $\mathrm{CO}_{2}$ is preferable for euthanasia due to the rapidity of effects and lack of muscle rigidity and spasms. Finally, the authors did not rule out that $\mathrm{CO}_{2}$ could have caused a stress effect.

Overall, argon is as easy to use as $\mathrm{CO}_{2}$, is non-flammable, and sinks to the bottom of the chamber since it is heavier than air, therefore reducing danger to those conducting the procedure. One drawback, however, is that argon is more expensive than $\mathrm{CO}_{2}$; however, utilizing a method that is less painful and distressful to the animals should take priority over cost. Moreover, the costs of both argon and $\mathrm{CO}_{2}$ are trivial compared with the total financial investment in an animal when all real costs are taken into account (e.g. technician and investigator time, costs of the animal and the animal's care, etc.).

\section{Decapitation}

Decapitation is a possible alternative to the use of $\mathrm{CO}_{2}$ for the euthanasia of (relatively) small numbers of animals, but this remains somewhat controversial. Mikeska and Klemm (1975) found that decapitation causes an EEG trace for an average duration of $13.6 \mathrm{~s}$; this study led to much of the controversy surrounding decapitation and previous recommendations by the AVMA $(1986,1993)$ that decapitation should not be done without justification.

Various authors have since challenged Mikeska and Klemm's (1975) findings. For example, Allred and Berntson (1986) presented a counter-argument, citing references that demonstrated an activated EEG pattern after hypoxia or damage to the lower brain stem as evidence that the Mikeska and Klemm data did not necessarily provide evidence of consciousness and distress. Vanderwolf et al. (1988) conducted studies that examined the source of low voltage fast activity (LVFA) and found that such EEG traces are not associated with noxious stimuli or consciousness. Additionally, Derr (1991) reported that it would take $2.7 \mathrm{~s}$ for a decapitated rat's head to become anoxic (indicating a presumed loss of consciousness).

Finally, Holson (1992) found that, by 1986, all eight papers reporting on the EEG of decapitated rodent heads agree that decapitation triggers an immediate, slow direct current EEG trace of 2-4 s duration followed by an LVFA trace that is usually gone in $10-13 \mathrm{~s}$, a pattern that is not associated with consciousness.

One reason that decapitation is sometimes chosen over other methods is that some agents, such as anaesthetics, can cause changes in tissue and alter brain metabolism parameters (see, e.g. Miller et al. 1988) and the aim of the study may be to collect 'undisturbed' tissue. In this case, however, it is important to consider that the stress of handling during the decapitation procedure may also modulate metabolite levels (e.g. Faupel et al. 1972). There may, of course, be occasions where the stress of handling is unlikely to change the parameters a scientist wishes to measure, but these should be readily justifiable.

In sum, decapitation produces an EEG trace that can last for 10-13 s, but the weight 
of the evidence indicates that consciousness following decapitation is unlikely to persist for more than 3-6s. It seems clear that decapitation produces a much quicker loss of consciousness than the recommended $\mathrm{CO}_{2}$ protocols. Therefore, from an animal welfare perspective, decapitation properly performed may be preferable to $\mathrm{CO}_{2}$. However, decapitation is not an easy procedure and technicians who use a guillotine must be properly trained and the equipment must be properly maintained.

\section{Recommendations and final discussion}

While $\mathrm{CO}_{2}$ has long been used as a method of euthanasia, questions have arisen that this practice may not fulfill the criteria for an easy and gentle death, as required by both ethical concerns and policy. The primary concerns are that exposure to $\mathrm{CO}_{2}$ gas may be painful; $\mathrm{CO}_{2}$ may cause onset of asphyxia while the animal is still conscious; physiological effects of $\mathrm{CO}_{2}$ on nasal mucosae and on the autonomic nervous system may be distressing; the cognitive/ perceptual/behavioural effects of $\mathrm{CO}_{2}$, such as ataxia, may be disturbing to the animal; and the process of $\mathrm{CO}_{2}$ inhalation may be highly aversive. Some or all of these results may cause pain and distress.

Information regarding concerns with the use of $\mathrm{CO}_{2}$ for euthanasia, described in this review, has led organizations such as The Humane Society of the United States to recommend changes, such as the use of an inhalant pre-anaesthetic in conjunction with $\mathrm{CO}_{2}$ for euthanasia of a large number of surplus rodents or a few to moderate number of rodents being used for research.

Decapitation is strongly discouraged when large numbers of animals are being euthanized because of the chances for operator error. For euthanasia of relatively few rodents being used for research that does not permit contamination of tissues, The Humane Society of the United States recommends decapitation by well-trained personnel if there is scientific justification, and when $\mathrm{CO}_{2}$ in conjunction with a preanaesthetic has well-founded scientific concerns. The use of $\mathrm{CO}_{2}$ alone is strongly discouraged in all instances.

Personnel play a big role in the issues discussed in this paper. Proper training of personnel in all techniques is essential for improved animal welfare. Centralized facilities in which the veterinary care staff performs such techniques are recommended; it is easier to ensure adequate training in centralized facilities and the expertise is typically higher among those who are performing euthanasia.

We recognize that many clinical veterinarians and laboratory animal technicians appear to be comfortable with $\mathrm{CO}_{2}$ alone as a euthanasia agent. However, we would argue that the conflicting data in the literature and the arguments around prefilled chambers versus GI, the presence or absence of oxygen, the lack of agreement on time to unconsciousness and the fact that $\mathrm{CO}_{2}$ produces significant physiological changes and behavioural indicators of pain and distress, all demand a careful reassessment of the use of the gas by itself as a euthanasia agent. Careful studies of distress and objective assessments of such distress using behavioural and physiological measures are clearly possible, as evidenced by the progress made in assessing farm animal welfare (see, for example, Appleby \& Hughes 1997).

The limitations in the currently available data outlined above (such as small sample sizes, examination of only certain measures while excluding others, and so on) suggest the need for a structured, multi-factorial study utilizing a range of dependent physiological and behavioural measures, evaluating a representative range of modes of $\mathrm{CO}_{2}$ and $\mathrm{CO}_{2}$-gas mixture exposures. This type of study would reveal the effects of $\mathrm{CO}_{2}$ exposure while controlling for methodological and procedural differences in practice between institutions. Most importantly, with effective coordination, this type of study could be completed without incurring further potential animal distress, by gathering data from existing practices, with welfare measures taken as add-on to procedures that would be performed on existing animals. This type of applied animal 
welfare research has already led to significant increases in the understanding of animal distress within the farm animal arena (e.g. King 2003).

Acknowledgements We would like to thank Victoria Hampshire and our colleagues Cheryl Ross and Gina Alvino for their contribution to this review. We would also like to thank all of the laboratory animal personnel who shared their expertise on this issue with us.

\section{References}

Allred JB, Berntson GG (1986) Is euthanasia of rats by decapitation humane? Journal of Nutrition 116, 1859-61

Alvaro RE, de Almeida V, Kwiatkowski K, Cates D, Kryger M, Rigatto H (1993) A developmental study of the dose-response curve of the respiratory sensory reflex. American Review of Respiratory Disease 148, 1013- 17

Ambrose N, Wadham J, Morton D (2000) In: Refinement of Euthanasia. Progress in the Reduction, Refinement and Replacement of Animal Experimentation (Balls M, van Zeller AM, Halder ME, eds). Amsterdam: Elsevier

Anton F, Euchner I, Handwerker HO (1992) Psychophysical examination of pain induced by defined $\mathrm{CO}_{2}$ pulses applied to the nasal mucosa. Pain 49, $53-60$

ANZCCART (Australian and New Zealand Council for the Care of Animals in Research and Teaching) (2001) In: Euthanasia of Animals Used for Scientific Purposes. 2nd edn. (JS Reilly, ed). Australia: Glen Osmond

Appleby MC, Hughes BO (1997) Animal Welfare. Wallingford: CAB International

AVMA (American Veterinary Medicine Association) (2001) 2000 Report of the AVMA panel on euthanasia. Journal of the American Veterinary Medical Association 218, 669-96

Barbaccia ML, Roscetti G, Trabucchi M, et al. (1996) Time-dependent changes in rat brain neuroactive steroid concentrations and $\mathrm{GABA}_{\mathrm{A}}$ receptor function after acute stress. Neuroendocrinology 63, 166-72

Blackshaw JK, Fenwick DC, Beattie AW, Allan DJ (1988) The behaviour of chickens, mice and rats during euthanasia with chloroform, carbon dioxide and ether. Laboratory Animals 22, 67-75

Britt DP (1986) The humaneness of carbon dioxide as an agent of euthanasia for laboratory rodents. In: Euthanasia of Unwanted, Injured or Diseased Animals for Educational or Scientific Purposes. London: Universities Federation for Animal Welfare

Canadian Council on Animal Care (1993) Guide to the Care and Use of Experimental Animals. Vol 1. 2nd edn. (Olfert ED, Cross BM, McWilliam AA, eds). Ontario, Canada: CCAC

Close B, Banister K, Baumans V, et al. (1996)

Recommendations for euthanasia of experimental animals: Part 1. DGXI of the European Commission. Laboratory Animals 30, 293-316

Close B, Banister K, Baumans V, et al. (1997) Recommendations for euthanasia of experimental animals: Part 2. DGXT of the European Commission. Laboratory Animals 31, 1-32

Coates EL (2001) Olfactory $\mathrm{CO}_{2}$ chemoreceptors. Respiration Physiology 129, 219-29

Coenen AM, Drinkenburg WHIM, Hoenderken R, van Luijtelaar ELJM (1995) Carbon dioxide euthanasia in rats: oxygen supplementation minimizes signs of agitation and asphyxia. Laboratory Animals 29, $262-8$

Danneman PJ, Stein S, Walshaw SO (1997) Humane and practical implications of using carbon dioxide mixed with oxygen for anaesthesia or euthanasia of rats. Laboratory Animal Science 47, 376-85

Dawkins MS (1990) From an animal's point of view: motivation, fitness and animal welfare. Behavioural and Brain Sciences 13, $1-9$

Derr RF (1991) Pain perception in decapitated rat brain. Life Sciences 49, 1399-402

Dripps RD, Comroe JH (1947) Respiratory and circulatory response of normal man to inhalation of 7.6 and 10.4 per cent $\mathrm{CO}_{2}$ with a comparison of the maximal ventilation produced by severe muscular exercise, inhalation of $\mathrm{CO}_{2}$ and maximal voluntary hyperventilation. American Journal of Physiology 149, 43-51

Eisele JH, Eger EI, Muallem M (1967) Narcotic properties of carbon dioxide in the dog. Anesthesiology 28, 856-65

European Commission (1996) Working Party Report: Recommendations for euthanasia of experimental animals: Part 1. Laboratory Animals 30, 293-316

European Commission (1997) Recommendations for euthanasia of experimental animals: Part 2. DGXT of the European Commission. Laboratory Animals 31, 1-32

Biotechnology Regulatory Atlas (homepage on the Internet) (cited 5 August 2004). Available from: http://plus.i-bio.gov.uk/ibioatlas/textc2_1.html

Farm Animal Welfare Council (2003) Report on the Welfare of Farmed Animals at Slaughter or Killing, Part 1: Red Meat Animals (monograph on the internet) London, England: Defra Publications (cited 2 September 2004). Available from: http:// www.fawc.org.uk/reports/slaughter/report.pdf

Faupel RP, Seitz HJ, Tarnowski W, Thiemann V, Weiss C (1972) The problem of tissue sampling from experimental animals with respect to freezing technique, anoxia, stress and narcosis. A new method for sampling rat liver tissue and the physiological values of glycolytic intermediates and related compounds. Archives of Biochemistry and Biophysics 148, 509-22 
Fawell JK, Thomson C, Cooke L (1972) Respiratory artefact produced by carbon dioxide and pentobarbitone sodium euthanasia in rats. Laboratory Animals 6, 321-6

Hackbarth H, Küppers N, Bohnet W (2000) Euthanasia of rats with carbon dioxide - animal welfare aspects. Laboratory Animals 34, 91-6

Hewett TA, Kovacs MS, Artwohl JE, Bennett BT (1993) A comparison of euthanasia methods in rats, using carbon dioxide in prefilled and fixed flow rate filled chambers. Laboratory Animal Science 43, 579-82

Hornett TD, Haynes AR (1984) Comparison of carbon dioxide/air mixture and nitrogen/air mixture for the euthanasia of rodents. Design of a system for inhalation euthanasia. Animal Technology 35, 93-9

Hoenderken R (1983) Electrical and carbon dioxide stunning of pigs for slaughter. In: Stunning Animals for Slaughter (Eikelenboom G, ed). Boston: Martinus Nijhoff Publishers, 59-63

Holson RR (1992) Euthanasia by decapitation: evidence that this technique produces prompt, painless unconsciousness in laboratory rodents. Neurotoxicology and Teratology 14, 253-7

Hummel T, Gruber M, Pauli E, Kobal G (1994) Chemo-somatosensory event-related potentials in response to repetitive painful chemical stimulation of the nasal mucosa. Electroencephalography and Clinical Neurophysiology 92, 426-32

International Association for the Study of Pain (1979) Pain terms: a list with definitions and notes on usage. Pain 6, 249

Iwarsson K, Rehbinder C (1993) A study of different euthanasia techniques in guinea pigs, rats, and mice. Animal response and postmortem findings. Scandinavian Journal of Laboratory Animal Science 20, 191-205

Jongman EC, Barnett JL, Hemsworth PH (2000) The aversiveness of carbon dioxide stunning in pigs and a comparison of the $\mathrm{CO}_{2}$ stunner crate vs. the Vrestrainer. Applied Animal Behaviour Science 67, 67-76

Kety SS, Schmidt CF (1947) The effects of altered arterial tensions of carbon dioxide and oxygen on cerebral blood flow and cerebral oxygen consumption of normal young men. Journal of Clinical Investigation 27, 484-92

King LA (2003) Behavioral evaluation of the psychological welfare and environmental requirements of agricultural research animals: theory, measurement, ethics and practical implications. ILAR Journal 44, 211-21

Kline BE, Peckham V, Heist HE (1963) Some aids in the handling of large numbers of mice. Laboratory Animal Care 13, 84-90

Kohler I, Meier R, Busato A, Neiger-Aeschbacher G (1999) Is carbon dioxide $\left(\mathrm{CO}_{2}\right)$ a useful short acting anaesthetic for small laboratory animals? Laboratory Animals 33, 155-61
Lawson DM, Sharp JL, Azar TA (2003) A comparison of carbon dioxide, argon and nitrogen for euthanasia of mice. Contemporary Topics in Laboratory Animal Science 42, 82

Leach M, Bowell VA, Allan TF, Morton DB (2002a) Degrees of aversion shown by rats and mice to different concentrations of inhalational anaesthetics. Veterinary Record 150, 808-15

Leach M, Bowell VA, Allan TF, Morton DB (2002b) Aversion to gaseous euthanasia agents in rats and mice. Journal of Comparative Medicine 52, 249-57

Martoft L, Stødkilde-Jørgensen H, Forslid A, Pedersen $\mathrm{HD}$, Jørgensen PF (2003) $\mathrm{CO}_{2}$ induced acute respiratory acidosis and brain tissue intracellular pH: a ${ }^{31} \mathrm{P}$ NMR study in swine. Laboratory Animals 37, 241-8

Mason G, Cooper J, Clarebrough C (2001) The welfare of fur-farmed mink. Nature 410, 35-6

Martin P, Bateson P (1993) Measuring Behaviour: An Introductory Guide. 2nd edn. Cambridge: Cambridge University Press

McArdle L (1959) Electrocardiographic studies during the inhalation of 30 per cent carbon dioxide in man. British Journal of Anaethesiology 31, 142-51

Mikeska JA, Klemm WA (1975) EEG evaluation of humaneness of asphyxia and decapitation euthanasia of the laboratory rat. Laboratory Animal Science 25, 175-9

Miller LP, Mayer S, Braun LD, Geiger P, Oldendorf WH (1988) The effect of pretreatment with phenobarbital on the extent of $[\mathrm{C}]$ incorporation from $[\mathrm{U}-$ C] glucose into various rat brain glycolytic intermediates: relevance to regulation at hexokinase and phosphofructokinase. Neurochemical Research 13, 377-82

Mischler SA, Alexander M, Battles AH, Raucci JA, Nalwalk JW, Hough LB (1994) Prolonged antinociception following carbon dioxide anesthesia in the laboratory rat. Brain Research 640, 322-7

OECD (2000) Guidance Document on the Recognition, Assessment, and Use of Clinical Signs as Humane Endpoints for Experimental Animals Used in Safety Evaluation. Paris, France: Organisation for Economic Co-operation and Development

Office of Laboratory Animal Welfare (2002) PHS Policy on Humane Care and Use of Laboratory Animals Clarification Regarding Use of Carbon Dioxide for Euthanasia of Small Laboratory Animals (cited 19 March 2004). Available from: http:// grants.nih.gov/grants/guide/notice-files/NOT-OD02-062.html

Public Health Service (1993) PHS Policy on Humane Care and Use of Laboratory Animals. Washington, DC: US Department of Health and Human Services

Raj ABM, Gregory NG (1994) An evaluation of humane gas stunning methods for turkeys. Veterinary Record 135, 222-3

Raj ABM, Gregory NG (1995) Welfare implications of the gas stunning of pigs 1 . Determination of 
aversion to the initial inhalation of carbon dioxide or argon. Animal Welfare 4, 273-80

Raj ABM, Gregory NG (1996) Welfare implications of the gas stunning of pigs 2. Stress of induction of anaesthesia. Animal Welfare 5, 71-8

Robb DH, Wotton SB, McKinstry JL, Sorensen NK, Kestin SC (2000) Commercial slaughter methods used on Atlantic salmon: determination of the onset of brain failure by electroencephalography. Veterinary Record 147, 298-303

Rolls ET (1999) The Brain and Emotion. Oxford: Oxford University Press

Simonsen HB, Thordal-Christensen A, Ockens N (1981) Carbon monoxide and carbon dioxide euthanasia of cats: duration and animal behaviour. British Veterinary Journal 137, 274-8

Smith W, Harrap SB (1997) Behavioural and cardiovascular responses of rats to euthanasia using carbon dioxide gas. Laboratory Animals 31, $337-46$

Thomas T, Spyer KM (2000) ATP as a mediator of mammalian central $\mathrm{CO}_{2}$ chemoreception. Journal of Physiology 523, 441-7

Thurauf N, Friedel I, Hummel C, Kobal G (1991) The mucosal potential elicited by noxious chemical stimuli with $\mathrm{CO}_{2}$ in rats: is it a peripheral nociceptive event? Neuroscience Letters 128, 297-300
United Kingdom Home Office. Code of Practice for the Humane Killing of Animals under Schedule 1 to the Animals (in Scientific Procedures) Act 1986 (monograph on the internet). London, England, 1997 (cited 29 March 2004). Available from http:// www.homeoffice.gov.uk/docs/hc193.html

Universities Federation for Animal Welfare (UFAW) (1986) Euthanasia of Unwanted, Injured or Diseased Animals for Educational or Scientific Purposes. Proceedings of a symposium organized by UFAW in association with the Humane Slaughter Association. Hertfordshire, England: Universities Federation for Animal Welfare

US Department of Agriculture (1997) Policy \#11: Painful/Distressful Procedures. 14 April 1997 (cited 5 August 2004). Available from: http:// www.aphis.usda.gov/ac/policy/policy11.pdf

Vanderwolf CH, Buzsaki G, Cain DP, Cooley RK, Robertson B (1988) Neocortical and hippocampal electrical activity following decapitation in the rat. Brain Research 451, 340-4

Woodbury DM, Rollins LT, Gardner MD, et al. (1958) Effects of carbon dioxide on brain excitability and electrolytes. American Journal of Physiology 192, 79-90

Woodbury DM, Karler R (1960) The role of carbon dioxide in the nervous system. Anesthesiology 21, 686-703 